\title{
DIFFUSION LAW FOR THE DISPERSION OF HARD PARTICLES IN AN ICE MATRIX THAT UNDERGOES SIMPLE SHEAR DEFORMATION
}

\author{
By J. WeERTMAN* \\ (U.S. Army Cold Regions Research and Engineering Laboratory, Hanover, \\ New Hampshire 03755, U.S.A.)
}

\begin{abstract}
A diffusion equation is obtained that describes the mechanical dispersion of a dilute mixture of solid particles within an ice matrix that is undergoing deformation. It is shown that within the limits of time intervals and strain-rates appropriate to the movement of glaciers and ice sheets, the dispersal distance usually is no larger than a distance about one order of magnitude greater than the size of the particles themselves.

RÉsumé. Loi de diffusion pour la dispersion de particules dures dans une matrice de glace soumise à une simple déformation de cissaillement. Il a été obtenu une équation de diffusion qui décrit la dispersion mécanique d'un mélange dilué de particules solides dans une matrice de glace soumise à déformation. Il est montré que dans les limites d'intervalles de temps et de valeurs de contrainte appropriées au mouvement des glaciers et indlandsis, la distance de dispersion est d'ordinaire pas plus grande qu'une distance d'environ un ordre de grandeur de plus que la taille des particules elles-mêmes.

Zusammenfassung. Das Diffusionsgesetz für die Dispersion harter Partikel in Eis, welches einfachen Scherdeformationen unterliegt. Eine Diffusionsgleichung für die mechanische Dispersion einer verdünnten Mischung von festen Partikeln in sich verformendem Eis wird aufgestellt. Es wird gezeigt, dass innerhalb der Zeitspannen und Spannungswerte, wie sie bei der Bewegung von Gletschern und Eisschilden auftreten, der Dispersionsabstand gewöhnlich nicht grösser ist als eine Strecke, welche das Format der Partikel selbst um etwa eine Grössenordnung übertrifft.
\end{abstract}

\section{INTRODUCTION}

Boulton (1967) has made the reasonable suggestion that solid particles in ice can be dispersed as a result of shear deformation. The theory of Bagnold (1954, 1966) that Boulton cites in support of this suggestion is not very useful for obtaining an estimate of how much dispersion should occur in ice at a given shear strain. Bagnold's theory was developed for a Newtonian fluid of either small or large viscosity. The theory was cast in terms of finding a "dispersive pressure" that could be measured in a laboratory experiment.

We wish to show in this paper that merely from geometric arguments it is possible to derive the diffusion law that describes the dispersion of second-phase particles in a solid matrix (e.g. ice) that undergoes simple shear deformation. This theory is applicable only to dilute dispersions of hard, essentially undeformable second-phase particles. The diffusion that occurs is independent of the particular flow law that governs the plastic shear strain of the matrix. Once the diffusion law is known the amount of dispersion for a particular problem can be found. Application of the diffusion law shows that this dispersal mechanism is not responsible for the "dirty" ice layer that exists at the bottom of the Greenland ice sheet at "Camp Century".

\section{THEORY}

The physical origin of the dispersion of particles in a matrix that undergoes shear deformation is obvious. Consider Figure I. Figure Ia shows two spherical particles of radius $a$ that are separated by a vertical distance $h$, where $h<2 a$. The deformation causes the upper particle to move to the right with respect to the lower particle. After the two particles collide their vertical separation must increase to $h^{\prime}$, where $h^{\prime}>h$. This increased separation is illustrated in Figure $\mathrm{Ib}$. It is inevitable that particles will be dispersed throughout the matrix by this collision process.

* Permanent address: Materials Science Department and Geology Department, Northwestern University, Evanston, Illinois 60201 , U.S.A. 


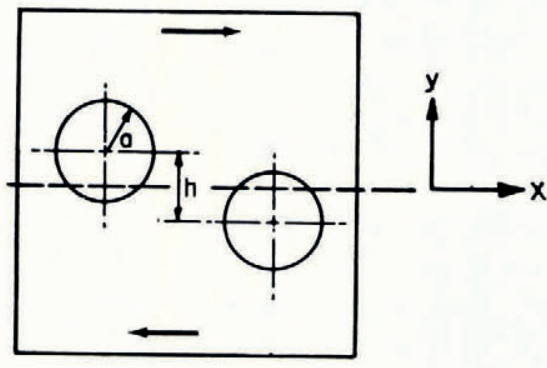

a.

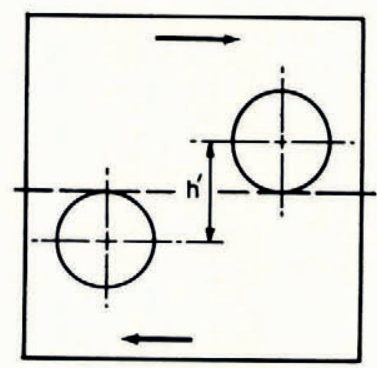

b.

Fig. 1. (a) before, (b) after collision of two particles

Consider how the diffusion law for the dispersal of particles may be obtained. The following assumptions and approximations now are made: The particles are hard and do not themselves deform. They are spheres and have a uniform size. The matrix undergoes only simple shear. The term "simple shear" means that the matrix shown in Figure I has a velocity component in the horizontal $x$ direction but no velocity component in the horizontal $z$ or vertical $y$ direction. The increase in separation of two colliding particles is not reduced after the collision through any relaxation effects or through some complex stress state in the surrounding matrix. The motion of the center of each particle, other than during periods of collisions, is the same as that which would occur if the sphere were replaced by matrix material. The average spacing between the particles is greater than their diameter.

The probability PSy (per unit time) that a sphere situated at the origin will collide with another sphere separated from it by a positive (or negative) vertical distance lying between $y$ and $y+\delta y$ is $2 C \dot{\epsilon}|y|\left(4 a^{2}-y^{2}\right)^{\frac{1}{2}} \delta y$, where $C$ is the number of particles per unit volume and $\dot{\epsilon}$ is the absolute value of the (engineering) shear strain-rate $(\dot{\epsilon}=\partial u / \partial y$, where $u$ is the horizontal velocity in the $x$ direction of the matrix).

This expression can be derived from the similar expression that appears in the preceding paper of this issue. Note that for a fixed value $y$ a collision between two spheres can take place for all values of $z$ (in the notation of that paper) such that $\left(z^{2}+y^{2}\right)^{\frac{1}{2}} \leqslant 2 a$. Therefore collisions take place with particles whose $z$ coordinates lie in the range

$$
-\left(4 a^{2}-y^{2}\right)^{\frac{1}{2}} \leqslant z \leqslant\left(4 a^{2}-y^{2}\right)^{\frac{1}{2}} .
$$

The vertical separation between two colliding particles increases as a result of collision. The increase in separation depends on the particular paths taken by the colliding spheres during the collision process. Suppose that the projections onto a plane perpendicular to the $x$ axis of the paths taken by the center of each of the two spheres are always radial. Under this assumption spheres separated by a vertical distance $h$ before collision will be separated an average distance $\bar{h}(h)=\left\{2 a h /\left(4 a^{2}-h^{2}\right)^{\frac{1}{2}}\right\} \ln \left\{\left[\left(4 a^{2}-h^{2}\right)^{\frac{1}{2}}+2 a\right] / h\right\}$ after the collision. Each sphere is, of course, displaced by an average amount $\frac{1}{2}(\bar{h}-h)$ in the vertical direction. The two colliding spheres are displaced in opposite directions.

As a result of collisions a particle moves with respect to the matrix with a velocity whose average vertical component $V$ is equal to the product of the number of collisions per unit time and the average vertical displacement produced by a collision. Account must be taken of the fact that some collisions cause downward displacements and others upward displacements. The following equation is found for $V$ :

$$
V=-\frac{1}{2} \int_{-2 a}^{2 a} P\{\bar{h}(y)-y\} \mathrm{d} y
$$

where the origin has been placed at the center of the particle under consideration. 
If both $C$ and $\dot{\epsilon}$ are independent of $y$, Equation ( $\mathrm{I}$ ) predicts, as it must, that $V=0$. If these two quantities are functions of $y$ and $z$ and they do not vary too strongly over distances of the order of $2 a$, the integral of Equation (I) can be evaluated by making use of the approximation $C \dot{\epsilon}=(C \dot{\epsilon})_{y=0, z=0}+y \partial(C \dot{\epsilon}) / \partial y+z \partial(C \dot{\epsilon}) / \partial z$. The following result is obtained:

$$
V=-\frac{1}{15}(2 a)^{5} \partial(C \dot{\epsilon}) / \partial y \text {. }
$$

A particle also may move with respect to the matrix in the $z$ direction. The $z$ component of velocity, $W$, can be found from an analysis similar to that just presented.

$$
W=-\frac{1}{30}(2 a)^{5} \partial(C \dot{\epsilon}) / \partial z .
$$

The rate of change of the particle concentration with time, $\partial C / \partial t$, is equal to $-\partial(V C) / \partial y$ when $C$ or $\dot{\epsilon}$ do not depend on $x$ or $z$. Thus, the one-dimensional diffusion equation that describes the dispersion of spherical particles in a matrix undergoing simple shear is

$$
\partial C / \partial t=\frac{1}{15}(2 a)^{5} \partial\{C \partial(C \dot{\epsilon}) / \partial y\} / \partial y .
$$

If the shear strain rate $\dot{\epsilon}$ is a constant this equation reduces to the classic diffusion equation

$$
\partial C / \partial t=\partial\{D \partial C / \partial y\} / \partial y
$$

where $D$ is a concentration-dependent diffusion constant given by

$$
D=\frac{1}{15}(2 a)^{5} C \dot{\epsilon}
$$

Equation (6a) can be rewritten as

$$
D=(8 / 5 \pi) a^{2} V^{\star}
$$

where $V^{\star}=(4 \pi / 3) a^{3} C$ is the total volume of the particles in a unit volume.

If $D$ is independent of the particle concentration $C$, the characteristic diffusion distance $\lambda$ obtained from solutions of Equation (5) is

$$
\lambda=(4 D t)^{\frac{1}{2}} \text {. }
$$

This expression gives the average distance moved in a time $t$ by a diffusing entity. Equation (7) sets an upper limit to the distance a particle can diffuse in time $t$ when the maximum value of $C$ (or $V^{\star}$ ) is used to calculate $D$. Table I lists values of $\lambda$ obtained from Equation (7) if it is assumed that the maximum value of $V^{\star}$ is 0.1 and $\dot{\epsilon}=0.1 /$ year. Various values of $a$ and $t$ were used to obtain the calculated $\lambda$ 's. The actual diffusion distance of a particle is of the same magnitude as these listed upper limits.

\section{Discussion}

\begin{tabular}{|c|c|c|c|c|}
\hline$a$ & I year & I0o years & ${ }^{1} 0^{4}$ years & $10^{6}$ years \\
\hline $0.1 \mathrm{~mm}$ & $7.1 \times 10^{-3}$ & 0.0071 & 0.071 & $0.7 \mathrm{I}$ \\
\hline $1 \mathrm{~mm}$ & $0.007 \mathrm{I}$ & 0.071 & 0.71 & 7.1 \\
\hline I $\mathrm{cm}$ & $0.07 \mathrm{I}$ & 0.71 & 7.1 & 71 \\
\hline $10 \mathrm{~cm}$ & 0.71 & $7 \cdot \mathrm{I}$ & 71 & $7.1 \times 10^{2}$ \\
\hline $1 \mathrm{~m}$ & 7.1 & 71 & $7.1 \times 10^{2}$ & $7.1 \times 10^{3}$ \\
\hline
\end{tabular}

Table I demonstrates that for the diffusion distance of a particle to be an order of magnitude larger than the size of the particle itself the total shear strain must exceed 1 ooo (or $10^{5}$ per cent). This fact implies that dispersion could be important only in very old glacier ice since the strain-rate of $\dot{\epsilon}=$ o. I/year used in Table I is a typical value for glaciers and ice sheets.

Table I. Upper Limits to Average Diffusion Distance $\lambda$ (IN CM) for $V^{\star}=0.1$ and $\dot{\epsilon}=0.1 /$ Year

The oldest ice in an ice sheet with no appreciable ablation area exists at and near its bottom surface. An immediate question that comes to mind is whether or not the dispersion mechanism can cause appreciable incorporation of rock, sand, silt, etc., from the glacier bed 
into the body of the glacier. At "Camp Century", for example, I $7 \mathrm{~m}$ of "dirty" ice were found at the bottom of the ice sheet (Hansen and Langway, I966). Behrendt ( I963), Bentley [ $\left.{ }^{\mathrm{r}}{ }_{964}{ }_{4}\right]$, and Bentley and Ostenso ( $196 \mathrm{r}$ ) believe that an ice layer containing morainal material underlies part of the Antarctic ice sheet and that this layer is up to $45^{\circ} \mathrm{m}$ thick.

So far there have been three mechanisms proposed to explain the incorporation of debris from the bed of an ice sheet into the body of an ice mass. Chamberlin (Chamberlin and Salisbury, I904, ch. 5) suggested movement of particles along a shear plane that extends to the bed. I presented (Weertman, I96I) a number of fundamental objections to this mechanism. In any event this mechanism presumably occurs only in regions of compressions. In extending regions that occur in areas of positive accumulation the "shear" planes should act in the reverse direction, bringing material down to the bed.

Hoekstra and Keeler (P. Hoekstra and C. Keeler, private conversation) have suggested that particles could diffuse into the ice when a temperature gradient is present. Hoekstra and Miller (1965) have shown experimentally that particles do move down temperature gradients in cold ice. However, if the experimental data of the drift velocity obtained by Hoekstra and Miller are used to calculate the expected thickness of the dirty ice layer at "Camp Century" it is found that the thickness so obtained is zero because the temperature gradient is such as to cause particles to move downwards.

I suggested (Weertman, I961, 1966) that debris could be incorporated into an ice mass if water should freeze to the bottom surface of an ice sheet. At present this mechanism cannot cause incorporation of morainal material at "Camp Century" because the temperature at the bottom of the ice sheet there is well below the freezing point. It appears likely that the bed remains below the freezing point upslope from "Camp Century" up to the divide of the ice sheet. On the other hand an analysis (Weertman, 1968) of the temperature profile of the "Camp Century" bore hole indicates that in the past either or both of the following conditions prevailed: (I) the ice temperatures were warmer; (2) the accumulation rate of snow at the upper surface was smaller than it is at present. Either of these situations could have led to the bottom surface being at the melting point and water being frozen to the bottom surface. Thus, the mechanism of freezing water could account for the recently discovered dirty ice layer at "Camp Century".

Boulton's is a fourth mechanism for the incorporation of particles into an ice mass. However, as will now be shown, this mechanism appears to be inadequate to account for the observations at "Camp Century". The particles that give the ice its dirty color cannot be seen by the naked eye (at least in part of one core examined by the author). Particle size studies have not yet been carried out on the dirty ice cores. Small pebbles can be seen in the cores (Hansen and Langway, I966). The dirty ice layer is about $17 \mathrm{~m}$ thick. The shear strain-rate at the bottom of the ice sheet at "Camp Century" is estimated (Weertman, I968) to be about 0.0 I5/year. The volume fraction $V^{\star}$ of particles has not been measured but is certainly not over about o.I. Thus, from Equation (7) and Table I it is possible to estimate that mechanical dispersion would have required at least ${ }^{10}{ }^{10}$ years to produce the dirty ice layer beneath "Camp Century". Therefore, this mechanism can be ruled out for this particular example.

The diffusion equation (5) does not take into account the longitudinal stretching of an ice sheet that occurs under its accumulation areas. Equation (5) was derived under the assumption that no vertical motion of ice takes place. Under an accumulation area the ice at a distance $y$ above the bed has an approximate velocity in the downward direction equal to $a^{\star} y / h$, where $a^{\star}$ is the accumulation rate and $h$ is the ice thickness. The following equation is a modification of Equation (5) that takes into account the effect of the vertical ice velocity

$$
\partial C / \partial t=\partial\{D \partial C / \partial y\} / \partial y+(a y / h) \partial C / \partial y .
$$

(It is assumed in this equation that the longitudinal strain-rate is smaller than the shear 
strain-rate. Then the mechanical dispersion arising from the longitudinal strain-rate is much smaller than that arising from the shear strain-rate and can be ignored.) Under steady-state conditions after an infinitely long time a particle could diffuse above the bed no higher than a characteristic diffusion distance $\lambda^{\prime}$ given by

$$
\lambda^{\prime}=\left(2 D h / a^{\star}\right)^{\frac{1}{2}} \text {. }
$$

Taking again $V^{\star}=0 . \mathrm{I}$ and $\dot{\epsilon}=0 . \mathrm{I} /$ year and assuming the typical values $h=2$ ooo $\mathrm{m}$ and $a^{\star}=20 \mathrm{~cm} /$ year, we find that $\lambda^{\prime}=10 \mathrm{~m}$ for boulders $\mathrm{I} \mathrm{m}$ in radius. For boulders $10 \mathrm{~m}$ in radius the dispersion distance $\lambda^{\prime}$ is $100 \mathrm{~m}$. Thus, appreciable dispersion of large boulders could occur at the bottom of an ice sheet. Boulton's mechanism thus may account for the postulated morainal layer beneath certain sections of the Antarctic ice sheet. In order to account for thicknesses of the order of $450 \mathrm{~m}$ it is clear that the boulders within the ice must have a large size (of the order of $20 \mathrm{~m}$ diameter or larger) and occur in a high concentration ( $V^{\star}$ of the order of 0.1 or greater). The mechanism is, therefore, just on the borderline of being able to furnish a plausible explanation for the presence of a morainal ice layer beneath the Antarctic ice sheet.

\section{Conclusion}

Within the limits of time intervals and strain-rates appropriate to the movement of glaciers and ice sheets, the mechanism that Boulton has proposed for the dispersion of particles within an ice mass causes the diffusion of particles out to distances which are, at the most, only about one order of magnitude larger than the size of the particles themselves.

\section{MS. received ${ }_{13}$ October ${ }_{1967}$}

\section{REFERENCES}

Bagnold, R. A. 1954. Experiments on a gravity-free dispersion of large solid spheres in a Newtonian fluid under shear. Proceedings of the Royal Society, Ser. A, Vol. 225, No. 1160, p. 49-63.

Bagnold, R. A. 1966. The shearing and dilatation of dry sand and the "singing" mechanism. Proceedings of the Royal Society, Ser. A, Vol. 295, No. 1442, p. 219-32.

Behrendt, J. C. 1963 . Seismic measurements on the ice sheet of the Antarctic Peninsula. Journal of Geophysical Research, Vol. 68, No. 21, p. 5973-90.

Bentley, C. R. [ $\left.{ }^{\mathrm{c}}{ }_{1}{ }^{64} 4\right]$. The structure of Antarctica and its ice cover. (In Odishaw, H., ed. Research in geophysics. Vol. 2. Solid earth and interface phenomena. Cambridge, Mass., M.I.T. Press, p. 335-89.)

Bentley, C. R., and Ostenso, N. A. 1961. Glacial and subglacial topography of West Antarctica. Journal of Glaciology, Vol. 3, No. 29, p. 882-91 1 .

Boulton, G. S. 1967. The development of a complex supraglacial moraine at the margin of Sørbreen, Ny Friesland, Vestspitsbergen. Journal of Glaciology, Vol. 6, No. 47, p. 71 7-35.

Chamberlin, T. C., and Salisbury, R. D. 1904. Geology. Vol. I. Second edition, revised. Ne w York, Henry Holt and Co.

Hansen, B. L., and Langway, C. C., ir. 1966. Deep core drilling in ice and core analysis at Camp Century, Greenland, 1961-1966. Antarctic Fournal of the United States, Vol. 1, No. 5, p. $207^{-08 .}$

Hoekstra, P., and Miller, R. D. 1965 . The movement of water in a film between glass and ice. U.S. Cold Regions Research and Engineering Laboratory. Research Report 153.

Weertman, J. 1961. Mechanism for the formation of inner moraines found near the edge of cold ice caps and ice sheets. Fournal of Glaciology, Vol. 3 , No. 3o, p. $965-78$.

Weertman, J. 1966. Effect of a basal water layer on the dimensions of ice sheets. Fournal of Glaciology, Vol. 6, No. 44, p. $191-207$.

Weertman, J. 1968. Comparison between measured and theoretical temperature profiles of the Camp Century, Greenland, bore hole. Journal of Geophysical Research, Vol. 73, No. 8, p. 2691-700. 